Audrey De Jong

Arun K. Baranwal Samir Jaber

\section{Predictors of difficult intubation in ICU: are children and adults alike?}

Received: 24 July 2014

Accepted: 29 July 2014

Published online: 28 August 2014

(C) Springer-Verlag Berlin Heidelberg and ESICM 2014

A. De Jong · S. Jaber $(\bowtie)$

Intensive Care Unit and Transplantation, Department of Anesthesia and Critical Care B (DAR B), Hôpital Saint-Éloi, CHU de

Montpellier, INSERM U1046, 80, Avenue Augustin Fliche,

34295 Montpellier Cedex 5, France

e-mail: s-jaber@chu-montpellier.fr

A. De Jong

e-mail: audreydejong@hotmail.fr

\section{A. K. Baranwal}

Pediatric Intensive Care Unit, Department of Pediatrics,

All India Institute of Medical Sciences-Patna,

Patna 801505, India

e-mail: baranwal1970@gmail.com

In a recent article in Intensive Care Medicine, Graciano et al. [1] reported difficult tracheal intubation (dTI) being associated with severe and non-severe tracheal intubation associated events (TIAEs) in pediatric ICUs (PICUs), and history of difficult airway and sign of upper airway obstruction (UAO) being independent predictors of dTI.

The issue of airway management has received increasing attention recently, both in adult ICUs [2-5] and PICUs [6-9]. The index study [1] is one of the few to assess the epidemiology and predictors of dTI in PICUs. Difficult TI was defined as a primary oral tracheal intubation (TI) course that failed or required three or more attempts by an experienced attending or fellow provider for successful $\mathrm{TI}$ and is similar to the definition used in adult studies [10-12]. The incidence of dTI was $9 \%$, similar to the incidence found in adult population $(11 \%)$ recently [10]. The main predictors of dTI in the adult population were related to anatomy (Mallampati score III or IV, obstructive sleep apnea syndrome, reduced mobility of cervical spine, limited mouth opening); pathology (severe hypoxia, coma); and provider (nonanesthesiologist) [10]. A seven-item MACOCHA score was then created, and the Mallampati score was given the highest weighting [10]. Similar anatomical predictive factors were evaluated in the index study as well [1] including UAO, small thyromental space, midface hypoplasia, and limited neck extension and mouth opening. Mallampati scoring was not done as it gives high false positive rates in pediatric patients [13], and is difficult to evaluate in critically ill children. Though UAO (evidenced by severe retraction and/or audible stridor) is easy to evaluate at the bedside, it may be challenging especially among children under five [9] because of major developmental differences [13]. The index study demonstrated UAO, small thyromental space, and limited neck extension and mouth opening to be associated with dTI on univariate analysis [1]. However on multivariate analysis, only UAO could be proved to be an independent anatomical predictor for dTI with and without stratified analysis by provider level (advanced vs non-advanced) making it the major predictor in PICU patients (32/129 vs 126/1,340; overall odds ratio irrespective of provider level $=3.18$ [1]) similar to adult patients (obstructive sleep apnea, OR $=5.97$ [10]) (Table 1). History of difficult intubation was another independent risk factor for dTI among the advanced first providers group, but not in the non-advanced first providers group.

Despite being significantly associated with dTI on univariate and multivariate analyses, the suboptimal sensitivity and negative predictive value of various difficult airway features including UAO indicate that absence of these features does not assure easy and smooth intubation. In adults [10], the MACOCHA score had high sensitivity $(73 \%)$ and negative predictive value $(98 \%)$, 
Table 1 Comparison of the candidate predictors of difficult tracheal intubation in adult and children in intensive care units

\begin{tabular}{|c|c|c|c|c|}
\hline & \multicolumn{2}{|l|}{$\begin{array}{l}\text { Univariate analysis } \\
p \text { value }\end{array}$} & \multicolumn{2}{|c|}{$\begin{array}{l}\text { Multivariate analysis } \\
\text { Odds ratio [95\% confidence interval] }\end{array}$} \\
\hline & Adult $(N=1,000)$ & Children $(N=1,469)$ & Adult $(N=694)$ & Children $(N=1,469)$ \\
\hline Upper airway obstruction & $<0.001$ & $<0.001$ & $5.97[2.68-13.23]$ & $3.18[2.00-4.81]$ \\
\hline Limited neck mobility & $<0.001$ & 0.008 & $3.87[1.58-9.52]$ & NS \\
\hline Limited mouth opening & $<0.001$ & 0.002 & $3.21[1.34-7.70]$ & NS \\
\hline Short thyromental space & 0.35 & 0.001 & NS & NS \\
\hline Age & 0.09 & 0.046 & $0.98[0.96-1.00]$ & NS \\
\hline Severe hypoxemia & 0.009 & 0.16 & $2.46[1.23-4.92]$ & NS \\
\hline Mallampati score & $<0.001$ & NA & $17.67[9.28-33.60]$ & NA \\
\hline Coma & 0.02 & NA & $2.26[1.16-4.39]$ & NA \\
\hline Non-anesthesiologist & 0.04 & NA & $2.03[1.07-3.85]$ & NA \\
\hline
\end{tabular}

Predictors of difficult tracheal intubation were assessed in an adult population in the study by De Jong et al. [10]. Predictors of difficult tracheal intubation were assessed in a pediatric population in the study by Graciano et al. presented in the current issue $N S$ not significant, $N A$ not assessed

with corresponding specificity of $89 \%$ and positive predictive value of $36 \%$ at a cutoff score of 3 . Developmental anatomical differences due to the wide range of patient age in the pediatric studies may be one of the limitations in predicting dTI. Age-specific stratification of the patients may be considered [9] in future to determine whether patients of a specific age group are at more risk for dTI, and whether one or more of the difficult airway features have high sensitivity and negative predictive value in them. Further, quantifying the UAO with the likes of modified Westley's croup score [9] and using a cutoff may increase sensitivity and negative predictive value of a specific level of UAO for dTI. It may be clinically beneficial to help inform intubation decisions in PICUs.

Interestingly, the study revealed advanced provider level to be associated with higher incidence of dTI [1]. The authors suggested a possible provider selection to match with anticipated TI difficulty, a practice widely prevalent in current PICUs. Further, there was less likelihood of rapid sequence induction and neuromuscular blocker use with dTI. Again the authors' explanation is potential intentional avoidance of these medications in patients with anticipated dTI to prevent consequences of "can't ventilate can't intubate" situations by maintaining spontaneous breathing. However, evaluation of the potential benefit of rapid sequence induction to prevent dTI or TIAEs, while keeping process measures other than medications constant, may be informative.

An important limitation of the study is the high percentage of missing data regarding long-term outcomes, e.g., length of intubation, length of PICU stay, or PICU mortality. However with improved databases, the issue of missing data may be better dealt with in future. Another limitation is the lack of an algorithm to inform the decision to intubate [14]. Some of the intubations (and thus dTIs) could have been avoided with the use of noninvasive ventilation [15] or high flow nasal prong therapy [16] leading to better outcome in terms of TIAEs. This potential of algorithms may be explored in future.

The authors used definitions of TIAEs similar to those in adult studies $[10,17]$. The severe and non-severe TIAEs were significantly higher in the dTI group. These happened despite precautions of having advanced providers and avoiding rapid sequence intubation medications for anticipated dTIs. The severe TIAEs were dominated by the cardiac arrests, and the non-severe ones by the esophageal intubation with immediate recognition. This association, most likely causative, underlies the need for improvement in the management of dTI in both pediatric and adult ICUs. The first step could be to develop and validate an algorithm for airway management $[14,18]$ according to the indications of intubation and the potential predictive factors of dTI in order to reduce TIAEs. Recent data suggest useful potential help provided by video-laryngoscopy in airway management of adults [11, 12]. Pediatric video-laryngoscopy devices need to be evaluated in PICUs [11, 12, 19].

To conclude, the index study [1] helps to understand the epidemiology of the dTI in PICU patients by documenting its incidence and associated risk factors. The study has added to the gradually but continuously increasing information on dTIs in the PICU population, with clues being taken from the adult studies. UAO was found to be the independent predictor of dTI. This is just the beginning; to improve the safety of airway management further we need more, and more detailed, studies.

\section{Conflicts of interest None.}




\section{References}

1. Graciano AL, Tamburro R, Thompson AE, Fiadjoe J, Nadkarni VM, Nishisaki A (2014) Incidence and associated factors of difficult tracheal intubations in pediatric ICUs: a report from National Emergency Airway Registry for Children: NEAR4KIDS. Intensive Care Med. doi: 10.1007/s00134-014-3407-4

2. Mosier JM, Law JA (2014) Airway management in the critically ill. Intensive Care Med 40:727-729. doi: 10.1007/s00134-014-3261-4

3. Dhonneur G, Zraier S, Sebbah JL, Haouache H (2014) Urgent face-to-face tracheal re-intubation using VideoAirtraq in ICU patients placed in the sitting position. Intensive Care Med 40:625-626. doi: 10.1007/s00134-014-3209-8

4. Schnell D, Timsit JF, Darmon M, Vesin A, Goldgran-Toledano D, Dumenil AS, Garrouste-Orgeas M, Adrie C, Bouadma L, Planquette B, Cohen Y, Schwebel C, Soufir L, Jamali S, Souweine B, Azoulay E (2014) Noninvasive mechanical ventilation in acute respiratory failure: trends in use and outcomes. Intensive Care Med 40:582-591. doi: 10.1007/s00134-014-3222-y

5. Lellouche F, L'Her E, Abroug F, Deye N, Rodriguez PO, Rabbat A, Jaber S, Fartoukh M, Conti G, Cracco C, Richard JC, Ricard JD, Mal H, Mentec H, Loisel F, Lacherade JC, Taille S, Brochard L (2014) Impact of the humidification device on intubation rate during noninvasive ventilation with ICU ventilators: results of a multicenter randomized controlled trial. Intensive Care Med 40:211-219. doi: 10.1007/s00134-013-3145-z

6. Argent AC, Biban P (2014) What's new on NIV in the PICU: does everyone in respiratory failure require endotracheal intubation? Intensive Care Med 40:880-884. doi: $10.1007 / \mathrm{s} 00134-014-3274-\mathrm{z}$
7. Jones P, Dauger S (2014) The benefits of nCPAP versus intubation for severe bronchiolitis. Intensive Care Med 40:763. doi: 10.1007/s00134-014-3245-4

8. Schlapbach LJ, Schaefer J, Brady AM, Mayfield S, Schibler A (2014) Highflow nasal cannula (HFNC) support in interhospital transport of critically ill children. Intensive Care Med 40:592-599. doi: 10.1007/s00134-014-3226-7

9. Baranwal AK, Meena JP, Singhi SC, Muralidharan J (2014) Dexamethasone pretreatment for $24 \mathrm{~h}$ versus $6 \mathrm{~h}$ for prevention of postextubation airway obstruction in children: a randomized double-blind trial. Intensive Care Med. doi:10.1007/s00134-014-3358-9

10. De Jong A, Molinari N, Terzi N, Mongardon N, Arnal J-M, Guitton C, Allaouchiche B, Paugam-Burtz C, Constantin J-M, Lefrant J-Y, Leone M, Papazian L, Asehnoune K, Maziers N, Azoulay E, Pradel G, Jung B, Jaber S (2013) Early identification of patients at risk for difficult intubation in ICU: development and validation of the MACOCHA score in a multicenter cohort study. Am J Respir Crit Care Med 187:832-839. doi: 10.1164/rccm.201210-1851OC

11. De Jong A, Molinari N, Conseil M, Coisel Y, Pouzeratte Y, Belafia F, Jung B, Chanques G, Jaber S (2014) Video laryngoscopy versus direct laryngoscopy for orotracheal intubation in the intensive care unit: a systematic review and meta-analysis. Intensive Care Med 40:629-639. doi: 10.1007/s00134-014-3236-5

12. De Jong A, Clavieras N, Conseil M, Coisel Y, Moury PH, Pouzeratte Y, Cisse M, Belafia F, Jung B, Chanques G, Molinari N, Jaber S (2013) Implementation of a combo videolaryngoscope for intubation in critically ill patients: a before-after comparative study. Intensive Care Med 39:2144-2152. doi: $10.1007 / \mathrm{s} 00134-013-3099-1$
13. de Caen A, Duff J, Coovadia AH, Luten R, Thompson AE, Hazinski MF (2008) Airway management. In: Nichols DG (ed) Roger's textbook of pediatric intensive care, 4th edn. Lippincott Williams \& Wilkins, Philadelphia, pp 303-322

14. De Jong A, Jung B, Jaber S (2014) Intubation in the ICU: we could improve our practice. Crit Care 18:209. doi:10.1186/cc13776

15. Ganu SS, Gautam A, Wilkins B, Egan J (2012) Increase in use of non-invasive ventilation for infants with severe bronchiolitis is associated with decline in intubation rates over a decade. Intensive Care Med 38:1177-1183. doi: 10.1007/s00134-012-2566-4

16. Schibler A, Pham TM, Dunster KR, Foster K, Barlow A, Gibbons K, Hough JL (2011) Reduced intubation rates for infants after introduction of high-flow nasal prong oxygen delivery. Intensive Care Med 37:847-852. doi: 10.1007/s00134-011-2177-5

17. Jaber S, Amraoui J, Lefrant J-Y, Arich C, Cohendy R, Landreau L, Calvet Y, Capdevila X, Mahamat A, Eledjam J-J (2006) Clinical practice and risk factors for immediate complications of endotracheal intubation in the intensive care unit: a prospective, multiple-center study. Crit Care Med 34:2355-2361. doi:

10.1097/01.ccm.0000233879.58720.87

18. Jaber S, Jung B, Corne P, Sebbane M, Muller L, Chanques G, Verzilli D, Jonquet O, Eledjam J-J, Lefrant J-Y (2010) An intervention to decrease complications related to endotracheal intubation in the intensive care unit: a prospective, multiple-center study. Intensive Care Med 36:248-255. doi: $10.1007 / \mathrm{s} 00134-009-1717-8$

19. Larsson A, Dhonneur G (2013)

Videolaryngoscopy: towards a new standard method for tracheal intubation in the ICU? Intensive Care Med 39:2220-2222. doi:

10.1007/s00134-013-3118-2 